\begin{tabular}{|c|c|}
\hline \multirow{3}{*}{ 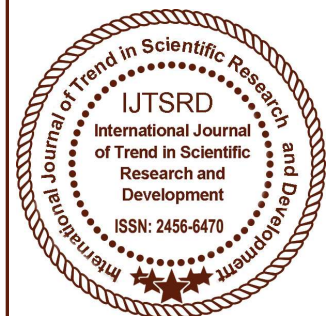 } & $\begin{array}{l}\text { International Journal of Trend in Scientific } \\
\text { Research and Development (IJTSRD) }\end{array}$ \\
\hline & International Open Access Journal \\
\hline & ISSN No: 2456 - 6470 | www.ijtsrd.com | Volume - 2 | Issue - 5 \\
\hline
\end{tabular}

\title{
An Assessment of Birth Control Measures Among Women in Reproductive Age of Kashmir
}

\author{
Suriya Gowhar ${ }^{1}$, Dr. Muzamil Jan ${ }^{2}$ \\ ${ }^{1}$ Research Scholar, ${ }^{2}$ Sr. Assistant Professor \\ Institute of Home Science, Kashmir, Jammu and Kashmir, India
}

\begin{abstract}
The present study was an attempt to assess the impact of age on attitude of married women regarding family planning and birth control measures and to find the level of adoption and impact of birth control measures adopted by married women of different age groups in Kashmir. The sample was selected through random sampling technique. For the sample, 400 married women were selected from different age groups. The sample was collected with the help of readymade scale namely, "Family planning and birth control scale" constructed by Ramachandrapa (1989) and self constructed questionnaire. The study shows medium level of impact of family planning and birth control measures is mostly on women $41-50$ years. A considerable section of women in the age group of 35 40 years have also shown high impact and adoption of family planning and birth control measures. Majority of women in the age group of 18-29 years have shown medium level of adoption of family planning and birth control measures.
\end{abstract}

Keywords: Birth control, measures, married women

\section{INTRODUCTION}

Family planning is a way of thinking and living that is adopted voluntarily, upon the basis of knowledge, attitudes and responsible decisions by individuals and couples, in order to promote health and welfare of the family group and thus contribute effectively to the social development of a country (WHO, 1971). Family planning is now recognized, as a basic human right. Its ultimate aim is to ensure decision on the part of its parents. Family planning helps people in many ways. It (a) helps a women to space her pregnancies in order to safeguard her health and that of her children: (b) protects a women from pregnancy until her body has been weaned and she wants to have another child; (c) gives parents the opportunity to provide a better start in life for each of their children; (d) helps men and women to enjoy their married life without fear of unwanted pregnancy; and (e) provides future well-being of the families (Mishra, 1992).

Birth control measures are preventive methods to help women avoid unwanted pregnancies. They include all temporary and permanent measures to prevent pregnancy. The last few years have witnessed a contraceptive revolution, that is, man trying to interfere with the ovulation cycle. The contraceptive methods may be broadly grouped into two classesspacing methods and terminal methods, they are

I. Spacing methods

1. Barrier Method

A. Physical methods

B. Chemical methods

C. Combined methods

2. Intra-Uterine Devices

3. Hormonal Methods

4. Post-Contraception Methods

5. Miscellaneous

II. Terminal Methods

1. Male Sterilization

2. Female Sterilization (Park, 1997)

\section{Review of Literature}

Oyedokun (2007) conducted a survey on determinants of Contraceptive Usage, Lessons from Women in Osun State, Nigeria. This paper analyses the awareness and utilization of modern contraceptive methods among 408 women of reproductive age 15- 
49 years in a Local Government area of Osun State, Nigeria. Results showed that although knowledge of contraceptive methods was high among these women, only 30.1 per cent ever used any of the known methods and less than a tenth were currently using any modern method at the time of the survey. Logistic regression result did not significantly support the hypotheses that knowledge of a method and number of children ever born will likely impact the use of modern contraceptive methods in the study area.

Hazarika (2010) conducted a survey on Women's Reproductive Health in Slum Populations in India: Evidence from NFHS-3. We examined a sample of 4,827 women in the age group of 15-49 years to assess the association of the variable slum with selected reproductive health services. All analyses were stratified by slum/non-slum residence, and multivariate logistic regression was used to analyze the strength of association between key reproductive health services and relevant socio demographic factors. We found that less than half of the women from the slum areas were currently using any contraceptive methods, and discontinuation rate was higher among these women. Sterilization was the most common method of contraception ( 25 per cent).

Shendge et al (2012) conducted a survey to assess the knowledge, attitude and practices of contraception in the women of reproductive age (15 to $45 \mathrm{yrs}$ ) group. This is a cross sectional observation study. Participants of this study included five hundred married women in the age group of 15 to $45 \mathrm{yrs}$ attending O.P.D of tertiary hospital's Obstetrics and Gynecology department. They were interviewed about their knowledge, attitude \& practices of contraception using fixed pre-formed questionnaires. 62.4 per cent uses contraception, however 54.33 per cent women discontinued afterwards and the reason cited was interest in child bearing. Practice of contraception increased with age and parity. Almost 99.7 per cent women had knowledge of female sterilization.

Eko et al (2013) conducted a survey to determining the prevalence of contraceptive use among women of reproductive age in Calabar Metropolis, southern Nigeria. A cross sectional survey was employed and a structured questionnaire was used to generate both qualitative and quantitative data from 305 respondents selected using the multi-stage stratified sampling technique. Majority of the respondents 107(35.1 per cent) were within the age group of 20-24 years and unmarried 204 (66.9 per cent). A greater proportion of the respondents were not currently using any contraceptives i.e. 239 (78.4 per cent). However, a handful of the respondents who currently use contraceptive methods uses male condom 27 (29.3 per cent) followed by pills 20(21.7 per cent) predominantly.

Kumar and Pujari (2014) conducted a survey to identify reasons for unmet need for contraception among reproductive age group in the community and to access the knowledge about modern methods of contraception among married women in the age group of 15-49 years of age. This cross-sectional study was conducted among the outpatient women attending the district hospital, Ananthapuramu and the study was carried out for two months from September to October 2013, among the women attending the outpatient departments of gynecology and obstetrics in the district hospital, Ananthapuramu district of Andhra Pradesh. The mean age of women in the study was 33.4 years and standard deviation (SD) 7.9 years and mean age of their husbands were 40.8 years and SD 9.0 years. 900 women were recorded and 850 were interviewed (94.4 per cent). Unmet need for contraception is to be addressed promptly and effectively out of bais owing to the control of population size and the health of a family thereby an ideal community.

\section{Objectives}

The present study is based on the following objectives

1. To assess the impact of age on attitude of married women regarding family planning and birth control measures in Kashmir

2. To find the level of adoption and impact of birth control measures adopted by married women of different age groups in Kashmir.

\section{Material and Methods}

The present study was conducted in Kashmir region of the J\&K state. The primary as well as secondary source of data was utilized to obtain the information. The sample for the study consisted of married women only, comprising age group of 18-50 years from rural and urban areas, illiterate as well as literate women. As per census 2011, the total population of married women in $\mathrm{J} \& \mathrm{~K}$ in the reproductive age group of 1549 years is 2011,867 . In order to calculate sample size for the present study the online "sample size calculator" was obtained from www.surveysystem.com/sscalc.htm. The sample size 
for present study was determined at the confidential level of 95 per cent with confidence interval of 5 . In this way, the sample size for present study was calculated as 384, which was finally considered as 400. Thus the sample for the present study comprised 400 married women in the age group of 18-50 years, out of which 200 were from rural areas (100 literate and 100 illiterate) and 200 were from urban areas (100 literate and 100 illiterate). The tools used for the present study comprised Self constructed questionnaire regarding, awareness, adoption, perception and impact regarding family planning and birth control measures. Moreover, Family planning and Birth Control Attitude Scale constructed by Dr. M. Rajamanickam (1998) was also used under the study. The data obtained through scale and questionnaire was consolidated, analyzed and interpreted as per the requirement of the objectives, using specific statistical tools for example percentage, chi-square and correlation. The $p$-value of $\leq 0.05$ was considered significant. IBM SPSS 20 Software was used for data analysis.

\section{Results and Discussion}

Table 1 indicates that, majority of women i.e. 84.75 per cent $(\mathrm{f}=339)$ have medium concern about adoption. This is true in the age group of 18-29 years by 87 per cent $(f=87)$ and 85 per cent $(f=85)$ in the age group of 30-34 years. This is also true within 3540 years old as well as 41-50 years old women by 77 per cent $(f=77)$ and 90 per cent $(f=90)$ respectively. Such concern within these age groups are found statistically insignificant $\chi^{2} \quad(6, \mathrm{~N}=400)=9.322, \mathrm{p}>$ 0.05 . Majority of women i.e. 73.75 per cent $(\mathrm{f}=295)$ have medium concern about adoption. This is true in the age group of $18-29$ years by 80 per cent $(\mathrm{f}=80)$ and 62 per cent $(\mathrm{f}=62)$ in the age group of $30-34$ years. This is also true within 35-40 years old as well as 41-50 years old women by 78 per cent $(\mathrm{f}=78)$ and 75 per cent $(\mathrm{f}=75)$ respectively. Such concern within these age groups are found statistically significant $\chi^{2}$ $(6, \mathrm{~N}=400)=17.831, \mathrm{p}<0.05$.

Table 2 depicts that majority of women i.e. 83.5 per cent $(\mathrm{f}=334)$ have high concern towards population problem. This is true in the age group of 18-29 years by 87 per cent $(f=87)$ and 84 per cent $(f=84)$ in the age group of 30-34 years. This is also true within 3540 years old as well as 41-50 years old women by 87 per cent $(\mathrm{f}=87)$ and 76 per cent $(\mathrm{f}=76)$ respectively. It is found that, most of the women i.e. 84.0 per cent $(\mathrm{f}=336)$ have high concern towards family planning.
This is true in the age group of 18-29 years by 89 per cent $(\mathrm{f}=89)$ and 83 per cent $(\mathrm{f}=83)$ in the age group of $30-34$ years This is also true within $35-40$ years old as well as 41-50 years old women by 86 per cent $(\mathrm{f}=86)$ and 78 per cent $(\mathrm{f}=78)$ respectively. Majority i.e. 87.75 per cent $(f=351)$ have medium concern about birth control. This is true in the age group of 18-29 years by 92 per cent $(\mathrm{f}=92)$ and 89 per cent $(\mathrm{f}=89)$ in the age group of 30-34 years This is also true within 35-40 years old as well as 41-50 years old women by 84 per cent $(\mathrm{f}=84)$ and 86 per cent $(\mathrm{f}=86)$ respectively. Additionally, bulk of women i.e. 61.75 per cent $(\mathrm{f}=247)$ have medium concern about fertility control. This is true in the age group of 18-29 years by 57 per cent $(\mathrm{f}=57)$ and 69 per cent $(\mathrm{f}=69)$ in the age group of 30-34 years This is also true within 35-40 years old as well as 41-50 years old women by 65 per cent $(f=65)$ and 56 per cent $(\mathrm{f}=56)$ respectively. Moreover, majority i.e. 71.75 per cent $(\mathrm{f}=287)$ have medium concern about birth control methods: abortion. This is true in the age group of $18-29$ years by 68 per cent $(\mathrm{f}=68)$ and 68 per cent $(\mathrm{f}=68)$ in the age group of 30 34 years This is also true within $35-40$ years old as well as 41-50 years old women by 72 per cent $(f=72)$ and 79 per cent $(\mathrm{f}=79)$ respectively. Most of the women i.e. 86.75 per cent $(\mathrm{f}=347)$ have medium concern about contraceptive method. This is true in the age group of $18-29$ years by 87 per cent $(\mathrm{f}=87)$ and 79 per cent $(f=79)$ in the age group of $30-34$ years This is also true within $35-40$ years old as well as 41 50 years old women by 90 per cent $(f=90)$ and 91 per cent $(\mathrm{f}=91)$ respectively. Mainly, 49.75 per cent $(\mathrm{f}=199)$ have medium concern about sterilization. This is true in the age group of 18-29 years by 58 per cent $(\mathrm{f}=58)$ and 48 per cent $(\mathrm{f}=48)$ in the age group of $30-34$ years. This is also true within $35-40$ years old as well as 41-50 years old women by 46 per cent $(\mathrm{f}=46)$ and 47 per cent $(\mathrm{f}=47)$ respectively. In addition, majority i.e. 93.5 per cent $(\mathrm{f}=374)$ have low concern about age of marriage. This is true in the age group of 18-29 years by 95.0 per cent $(f=95)$ and 95 per cent $(\mathrm{f}=95)$ in the age group of $30-34$ years. This is also true within $35-40$ years old as well as 41-50 years old women by 94 per cent $(\mathrm{f}=94)$ and 90 per cent $(\mathrm{f}=90)$ respectively. Furthermore, majority i.e. 86.5 per cent $(\mathrm{f}=346)$ have medium concern about overall attitude. This is true in the age group of 18-29 years by 87.0 per cent $(f=87)$ and 84 per cent $(f=84)$ in the age group of 30-34 years This is also true within 35-40 years old as well as 41-50 years old women by 90 per cent $(f=90)$ and 85 per cent $(f=85)$ respectively. 
Insignificant differences are observed among these age groups of women regarding their attitudinal levels for population problems $\chi^{2}(2, \mathrm{~N}=400)=8.494, \mathrm{p}>$ 0.05 , for family planning $\chi^{2}(2, \mathrm{~N}=400)=11.071, \mathrm{p}>$ 0.05 , for birth control $\chi^{2}(2, \mathrm{~N}=400)=6.412, \mathrm{p}>0.05$, for fertility control $\chi^{2}(2, \mathrm{~N}=400)=7.969, \mathrm{p}>0.05$, for birth control methods: abortion $\chi^{2}(2, \mathrm{~N}=400)=5.700, \mathrm{p}>0.05$, for contraceptive method

$\chi^{2}(2, \mathrm{~N}=400)=9.808, \mathrm{p}>0.05$, for sterilization

$\chi^{2}(2, \mathrm{~N}=400)=6.010, \mathrm{p}>0.05$, for age of marriage $\chi^{2}(2, \mathrm{~N}=400)=4.095, \mathrm{p}>0.05$ and for overall attitude $\chi^{2}(2, \mathrm{~N}=400)=6.154, \mathrm{p}>0.05$.

Table1. Adoption and awareness of birth control measures as per age of women

\begin{tabular}{|c|c|c|c|c|c|c|c|c|c|c|}
\hline & \multicolumn{10}{|c|}{ Age } \\
\hline & \multicolumn{2}{|c|}{$\begin{array}{c}\text { 18-29 Yrs } \\
(\mathrm{n}=100)\end{array}$} & \multicolumn{2}{|c|}{$\begin{array}{c}\begin{array}{c}30-34 \text { Yrs } \\
(\mathrm{n}=100)\end{array} \\
\end{array}$} & \multicolumn{2}{|c|}{$\begin{array}{c}\begin{array}{c}35-40 \text { Yrs } \\
(n=100)\end{array} \\
\end{array}$} & \multicolumn{2}{|c|}{$\begin{array}{c}\text { 41-50 Yrs } \\
(\mathrm{n}=100)\end{array}$} & \multicolumn{2}{|c|}{$\begin{array}{c}\text { Total } \\
(n=400)\end{array}$} \\
\hline & $\mathrm{F}$ & $\%$ & $\mathrm{~F}$ & $\%$ & $\mathrm{~F}$ & $\%$ & $\mathrm{~F}$ & $\%$ & $\mathrm{~F}$ & $\%$ \\
\hline \multicolumn{11}{|c|}{ Impact $\left(\chi^{2}=9.322, \mathbf{d f}=\mathbf{2}, \mathbf{p}\right.$-value $\left.=.156\right)(\mathrm{r}=-.031, \mathbf{p}$-value $=.532)$} \\
\hline High & 11 & 11.0 & 14 & 14.0 & 22 & 22.0 & 10 & \begin{tabular}{|l|}
10.0 \\
\end{tabular} & 57 & 14.2 \\
\hline Medium & 87 & 87.0 & 85 & 85.0 & 77 & 77.0 & 90 & 90.0 & 339 & 84.8 \\
\hline Low & 2 & 2.0 & 1 & 1.0 & 10 & 1.0 & 0 & 0.0 & 4 & 1.0 \\
\hline \multicolumn{11}{|c|}{ Adoption $\quad\left(\chi^{2}=17.831, \mathrm{df}=\mathbf{2}, \mathrm{p}\right.$-value $\left.=.007\right)(\mathrm{r}=-.046, \mathrm{p}$-value $=.359)$} \\
\hline High & 16 & 16.0 & 37 & 37.0 & 20 & 20.0 & 25 & 25.0 & 98 & 24.5 \\
\hline Medium & 80 & 80.0 & 62 & 62.0 & 78 & 78.0 & 75 & 75.0 & 295 & 73.8 \\
\hline Low & 4 & 4.0 & 1 & 1.0 & 2 & 2.0 & 0 & 0.0 & 7 & 1.8 \\
\hline
\end{tabular}

Based on field survey $(\mathrm{N}=400)$

$\mathrm{Df}$ denotes degree of freedom

$\chi 2$ denotes chi square

$\mathrm{P}$ denotes Kearl Pearson level of significance

$\mathrm{r}$ denotes spearman's correlation

Table2. Awareness levels regarding Family Planning and Birth Control Measures as per age of women

\begin{tabular}{|c|c|c|c|c|c|c|c|c|c|c|}
\hline & \multicolumn{8}{|l|}{ Age } & \multirow{2}{*}{\multicolumn{2}{|c|}{$\begin{array}{c}\text { Total } \\
(n=400)\end{array}$}} \\
\hline & \multicolumn{2}{|c|}{$\begin{array}{c}\text { 18-29 Yrs } \\
(\mathrm{n}=100)\end{array}$} & \multicolumn{2}{|c|}{$\begin{array}{c}\begin{array}{c}30-34 \text { Yrs } \\
(n=100)\end{array}\end{array}$} & \multicolumn{2}{|c|}{$\begin{array}{c}\begin{array}{c}35-40 \text { Yrs } \\
(\mathrm{n}=100)\end{array} \\
\end{array}$} & \multicolumn{2}{|c|}{$\begin{array}{c}\begin{array}{c}41-50 \text { Yrs } \\
(n=100)\end{array} \\
\end{array}$} & & \\
\hline & F & $\%$ & $\mathrm{~F}$ & $\%$ & $\mathrm{~F}$ & $\%$ & F & $\%$ & F & $\%$ \\
\hline \multicolumn{11}{|c|}{ 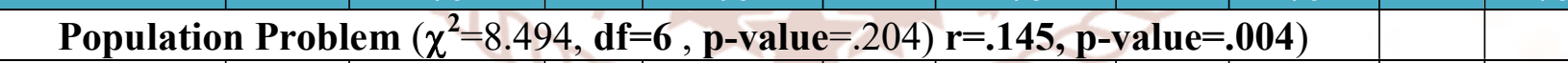 } \\
\hline High & 87 & $87.0 \%$ & 84 & $84.0 \%$ & 87 & $87.0 \%$ & 76 & $76.0 \%$ & 334 & 83.5 \\
\hline Medium & 13 & $13.0 \%$ & 16 & $16.0 \%$ & 12 & $12.0 \%$ & 22 & $22.0 \%$ & 63 & 15.8 \\
\hline Low & 0 & $0.0 \%$ & 0 & $0.0 \%$ & 1 & $1.0 \%$ & 2 & $2.0 \%$ & 3 & 0.8 \\
\hline \multicolumn{11}{|c|}{ Family Planning $\left(\chi^{2}=11.071, \mathbf{d f}=\mathbf{6}, \mathbf{p}\right.$-value $\left.=. .086\right)(\mathbf{r}=.157, \mathbf{p}$-value $=.002)$} \\
\hline High & 89 & $89.0 \%$ & 83 & $83.0 \%$ & 86 & $86.0 \%$ & 78 & $78.0 \%$ & 336 & 84.0 \\
\hline Medium & 11 & $11.0 \%$ & 17 & $17.0 \%$ & 11 & $11.0 \%$ & 18 & $18.0 \%$ & 57 & 14.2 \\
\hline Low & 0 & $0.0 \%$ & 0 & $0.0 \%$ & 3 & $3.0 \%$ & 4 & $4.0 \%$ & 7 & 1.8 \\
\hline \multicolumn{11}{|c|}{ Birth Control $\left(\chi^{2}=6.412, \mathbf{d f}=\mathbf{6}, \mathbf{p}\right.$-value $\left.=.379\right)(\mathbf{r}=-.029, \mathbf{p}$-value $=.563)$} \\
\hline High & 4 & $4.0 \%$ & 6 & $6.0 \%$ & 12 & $12.0 \%$ & 7 & $7.0 \%$ & 29 & 7.2 \\
\hline Medium & 92 & $92.0 \%$ & 89 & $89.0 \%$ & 84 & $84.0 \%$ & 86 & $86.0 \%$ & 351 & 87.8 \\
\hline Low & 4 & $4.0 \%$ & 5 & $5.0 \%$ & 4 & $4.0 \%$ & 7 & $7.0 \%$ & 20 & 5.0 \\
\hline \multicolumn{11}{|c|}{ Fertility control $\left(\chi^{2}=7.969, \mathbf{d f}=\mathbf{6}, \mathbf{p}\right.$-value $\left.=. .240\right)(\mathbf{r}=-.018, \mathbf{p}$-value $=.722)$} \\
\hline High & 35 & $35.0 \%$ & 25 & $25.0 \%$ & 23 & $23.0 \%$ & 33 & $33.0 \%$ & 116 & 29.0 \\
\hline Medium & 57 & $57.0 \%$ & 69 & $69.0 \%$ & 65 & $65.0 \%$ & 56 & $56.0 \%$ & 247 & 61.8 \\
\hline Low & 8 & $8.0 \%$ & 6 & $6.0 \%$ & 12 & $12.0 \%$ & 11 & $11.0 \%$ & 37 & 9.2 \\
\hline
\end{tabular}


International Journal of Trend in Scientific Research and Development (IJTSRD) ISSN: 2456-6470

\begin{tabular}{|c|c|c|c|c|c|c|c|c|c|c|}
\hline \multicolumn{11}{|c|}{ Birth Control Methods: Abortion $\left(\chi^{2}=5.700, \mathbf{d f}=\mathbf{6}, \mathbf{p}\right.$-value $\left.=. .458\right)(\mathbf{r}=-.028, \mathbf{p}-$ value $=.572)$} \\
\hline High & 25 & $25.0 \%$ & 22 & $22.0 \%$ & 23 & $23.0 \%$ & 16 & $16.0 \%$ & 86 & 21.5 \\
\hline Medium & 68 & $68.0 \%$ & 68 & $68.0 \%$ & 72 & $72.0 \%$ & 79 & $79.0 \%$ & 287 & 71.8 \\
\hline Low & 7 & $7.0 \%$ & 10 & $10.0 \%$ & 5 & $5.0 \%$ & 5 & $5.0 \%$ & 27 & 6.8 \\
\hline \multicolumn{11}{|c|}{ Contraceptive method $\left(\chi^{2}=9.808, \mathbf{d f}=\mathbf{6}, \mathbf{p}-\right.$ value $\left.=. .133\right)(\mathbf{r}=.064, \mathbf{p}$-value $=.205)$} \\
\hline High & 10 & $10.0 \%$ & 14 & $14.0 \%$ & 8 & $8.0 \%$ & 8 & $8.0 \%$ & 40 & 10.0 \\
\hline Medium & 87 & $87.0 \%$ & 79 & $79.0 \%$ & 90 & $90.0 \%$ & 91 & $91.0 \%$ & 347 & 86.8 \\
\hline Low & 3 & $3.0 \%$ & 7 & $7.0 \%$ & 2 & $2.0 \%$ & 1 & $1.0 \%$ & 13 & 3.2 \\
\hline \multicolumn{11}{|c|}{ Sterilization $\left(\chi^{2}=6.010, \mathbf{d f}=\mathbf{6}, \mathbf{p}\right.$-value $\left.=. .422\right)(\mathbf{r}=.050, \mathbf{p}$-value $=.744)$} \\
\hline High & 41 & $41.0 \%$ & 51 & $51.0 \%$ & 54 & $54.0 \%$ & 53 & $53.0 \%$ & 199 & 49.8 \\
\hline Medium & 58 & $58.0 \%$ & 48 & $48.0 \%$ & 46 & $46.0 \%$ & 47 & $47.0 \%$ & 199 & 49.8 \\
\hline Low & 1 & $1.0 \%$ & 1 & $1.0 \%$ & 0 & $0.0 \%$ & 0 & $0.0 \%$ & 2 & 0.5 \\
\hline \multicolumn{11}{|c|}{ Age of Marriage $\left(\chi^{2}=4.095, \mathbf{d f}=\mathbf{6}, \mathbf{p}\right.$-value $\left.=. .664\right)(\mathbf{r}=-.154, \mathbf{p}$-value $=.002)$} \\
\hline High & 1 & $1.0 \%$ & 1 & $1.0 \%$ & 0 & $0.0 \%$ & 1 & $1.0 \%$ & 3 & 0.8 \\
\hline Medium & 4 & $4.0 \%$ & 4 & $4.0 \%$ & 6 & $6.0 \%$ & 9 & $9.0 \%$ & 23 & 5.8 \\
\hline Low & 95 & $95.0 \%$ & 95 & $95.0 \%$ & 94 & $94.0 \%$ & 90 & $90.0 \%$ & 374 & 93.5 \\
\hline \multicolumn{11}{|c|}{ Attitude Overall $\left(\chi^{2}=6.154, \mathbf{d f}=\mathbf{6}, \mathbf{p}\right.$-value $\left.=.406\right)(\mathbf{r}=. \mathbf{0 6 0}, \mathrm{p}$-value $=. \mathbf{2 3 4})$} \\
\hline High & 12 & $12.0 \%$ & 15 & $15.0 \%$ & 7 & $7.0 \%$ & 11 & $11.0 \%$ & 45 & 11.2 \\
\hline Medium & 87 & $87.0 \%$ & 84 & $84.0 \%$ & 90 & $90.0 \%$ & 85 & $85.0 \%$ & 346 & 86.5 \\
\hline Low & 1 & $1.0 \%$ & 1 & $1.0 \%$ & 3 & $3.0 \%$ & 4 & $4.0 \%$ & 9 & 2.2 \\
\hline
\end{tabular}

Based on field survey $(\mathrm{N}=400)$

df denotes degree of freedom

$\chi 2$ denotes chi square

$\mathrm{P}$ denotes Kearl Pearson level of significance

$r$ denotes spearman's correlation

\section{Summary and Conclusion}

Family planning is sometimes used as a synonym or euphemism for the use of birth control; however, it often includes a wide variety of methods, and practices that are not birth control. It is most usually applied to a female-male couple who wish to limit the number of children they have and / or to control the timing of pregnancy (also known as spacing children). Family planning may encompass sterilization, as well as abortion. The study shows medium level of impact of family planning and birth control measures is mostly on women 41-50 years. A considerable section of women in the age group of 35-40 years have also shown high impact and adoption of family planning and birth control measures. Majority of women in the age group of 18-29 years have shown medium level of adoption of family planning and birth control measures. Despite many programmatic policies, reproductive health in India is very poorly understood. Primarily, in the Indian context, socio-cultural norms, beliefs and practices play a bigger role in making women more vulnerable to reproductive health problems. India has one of the highest rates of child marriage in the world, which increases reproductive health problems for girls because of early childbearing .The problem with early marriage and childbearing is that young girls are often not adequately prepared with information regarding reproductive and sexual health issues, including sexual intercourse, contraception, sexually transmitted infections and diseases (STIs and STDs), reproductive tract infections (RTIs), pregnancy and childbirth. The study shows medium level of impact of family planning and birth control measures is mostly on women 41-50 years. A considerable section of women in the age group of 35-40 years have also shown high impact and adoption of family planning and birth control measures. Majority of women in the age group of 18-29 years have shown medium level of adoption of family planning and birth control measures.

\section{References}

1. Calister, M.C., (1973). Readings in family planning: A challenge to the health professions. edition 1, 69-70.

2. Ferede, T., (2013). Multilevel Modeling of Modern Contraceptive Use among Rural and 
Urban Population of Ethiopia. American. Journal of Mathematics and Statistics, 3(1): 1-16.

3. Kamalifard, M., Malakouti, J., Pezeshki, M-Z., and Velayati, A., (2014). Continuation and Discontinuation Reasons of LD Contraceptives among Iranian Women. International journal of women's health and reproduction sciences, 2 (5): 287-290.

4. Medicine Net.Com, 1996-2015 "Definition of birth control" Health care media publishing company founded in 1996. http://www.medicinenet.com/script/main/mobilear t.asp?articlekey $=53351$.

5. Mischell, D.R "Family planning: contraception, sterilization and pregnancy termination". In: Katz, V.L., Lentz, G.M., Lobo, R.A., Gershenson, D.M., eds. Comprehensive Gynecology (2007) fifth ed. Philadelphia, PA: Mosby Elsevier, Chap 14. http://en.m.wikipedia.org/wiki/family_planning.

6. Ngome, E., and Odimegwu, C., (2014). The social context of use of modern contraceptives in Zimbabwe: a multilevel analysis. Reproductive health journal, 11(64): 1-14.

7. Skrine, R., (1984). The Practitioner, 229: 441-446 in Park, K., (1997) Text book of Preventive and Social Medicine, edition $5^{\text {th }}$ pp 322.

8. Solanki, H.M., Chavan, C. M. K., Velhal, G. D., and Parmar, M. T., (2013). A comparative study between met \& unmet need groups of contraception in rural area of Maharashtra, India. GLOBAL JOURNAL OF MEDICINE AND PUBLIC HEALTH, 2(1): 1-7.

9. Thyagarajan, S., Reji, B., and Viswan, S. P., (2014). Determinants of contraceptive usage in India. International Journal of Interdisciplinary and Multidisciplinary Studies (IJIMS), 1(10): 8897.

10. World Health Organization., (1971). Techn. Rep. Ser., No 483 in Park, K., (1997) Text book of Preventive and Social Medicine, edition $15^{\text {th }} \mathrm{pp}$ 319. 